\title{
Evolução dos preços das terras agrícolas no Paraná entre 1998 e 2015
}

\section{Farmland prices trends in Paraná state between 1998-2015}

\author{
Bruno Volsi ${ }^{1}$, Tiago Santos Telles ${ }^{1, \star}$ e Bastiaan Philip Reydon ${ }^{2}$ \\ ${ }^{1}$ Instituto Agronômico do Paraná, Rodovia Celso Garcia Cid, Km 375, CEP 86047-902 - Londrina/PR, Brasil \\ 2Instituto de Economia da Universidade Estadual de Campinas, Campinas/SP, Brasil \\ ( ${ }^{\star}$ E-mail: telles@iapar.br) \\ http://dx.doi.org/10.19084/RCA16129
}

Recebido/received: 2016.10.05

Recebido em versão revista/received in revised form: 2017.03.02

Aceite/accepted: 2017.03.07

\section{R E S U M O}

O objetivo deste estudo foi analisar a evolução dos preços das terras agrícolas no Paraná, nas suas micro e mesorregiões, entre 1998 e 2015. Para tanto, partindo de uma análise conjuntural, foram utilizados dados de preços de terras agrícolas do Paraná. Além disso, calculou-se o coeficiente de correlação de Pearson para aferir o grau de relação entre as principais variáveis levantadas acerca dos determinantes de preços de terras agrícolas paranaenses (valor bruto da produção agrícola, crédito rural, taxa de câmbio, taxa de juros e taxa de inflação) e o seu valor. Por fim, foi realizada uma análise de agrupamentos das microrregiões, pelo método de Ward, tendo por parâmetro o grau de semelhança do comportamento evolutivo dos preços de terras entre suas regiões. No período analisado, verificou-se uma valorização anual de 8,53\% no preço das terras agrícolas paranaense. A partir dos resultados, sobretudo os de correlação, foi possível inferir quando há uma elevação dos preços das commodities agrícolas, ou em períodos de forte desvalorização do real frente ao dólar, as terras tendem a se valorizar de modo mais intenso. Terras agrícolas muito valorizadas tornam seus preços menos sensíveis a mudanças conjunturais da economia.

Palavras-chave: mercado de terras, ativo econômico, commodities agrícolas.

\begin{abstract}
A B S T R A C T
The aim of this study was to analyze trends in farmland prices in Paraná, between 1998-2015. For this purpose, from a conjectural analysis, Paraná State farmland prices were used. In addition, the correlation among variables of main determinants of farmland prices in Paraná State (gross Production Value, rural credit, exchange rate, interest rate and inflation rate) was estimated by the Pearson correlation test. Finally a cluster analysis of Paraná State regions was made, through the Ward method, based on degree of similarity of farmland prices amongst Paraná State regions. During the analysis period, it was verified an annual increase of 8,53\% in farmland prices in Paraná. From the results, especially considering the correlation, it was possible to infer that farmland prices rise subsequently to an increase in agricultural commodities prices, or currency exchange variation. High valued farmland have prices less sensitive to changes in the economy.
\end{abstract}

Keywords: land market, economic asset, agricultural commodities. 


\section{INTRODUÇÃO}

A produtividade agrícola tem forte correlação com as mudanças nos preços das terras (Ferro e Castro, 2013; Oliveira e Ferreira, 2014; Malassise et al., 2015). O aumento da produtividade e dos preços dos produtos agrícolas, expressos pelas relações de troca na agricultura e respectivos rendimentos auferidos com as atividades agrícolas, podem tanto estimular a demanda por terras, valorizando o ativo, quanto reduzir os interesses dos produtores em ampliar suas áreas, arrefecendo a pressão sobre os seus preços.

Entretanto, a literatura econômica brasileira tem mostrado que alterações na taxa de juros, inflação, crédito rural, preços das commodities agrícolas e da taxa de câmbio, podem alterar os preços das terras agrícolas (Reydon e Plata, 2006; Telles et al., 2016). Esses estudos demonstram que os preços das terras não são determinados apenas pela rentabilidade decorrente das atividades agrícolas, mas também pelas expectativas dos agentes quanto à sua valorização, sobretudo em um ambiente econômico permeado por incertezas. Isto é, as alterações dos preços das terras agrícolas acabam acompanhando as mudanças e transformações da conjuntura econômica do país. Tais dicotomias dão conta da complexidade das análises referentes ao mercado de terras.

A maior parte dos estudos sobre preços de terras agrícolas no Brasil foi realizada considerando os preços médios para o país como um todo (Oliveira e Ferreira, 2014; Telles et al., 2016). Há uma escassa literatura com enfoque regional (Camargo et al., 2004; Ferro e Castro, 2013; Reydon et al., 2014). Mesmo no estado do Paraná, uns dos principais celeiros agropecuários do país, existem poucos estudos que tratam da dinâmica dos preços de suas terras agrícolas (Michellon e Reydon, 2003; Malassise et al., 2015), sendo que não há estudos acerca do comportamento dos preços de terras agrícolas em suas micro e mesorregiões. Além disso, na maioria das pesquisas documentadas buscou-se verificar os determinantes dos preços das terras agrícolas, sendo raros os trabalhos em que se discutiu a evolução de seus preços e a relação desta com os fenômenos e ações que permeiam a conjuntura econômica - vetores que influenciam os ciclos de valorização e desvalorização em uma economia.
O Paraná tem vantagem logística em relação aos demais estados, contando com um dos principais portos graneleiros do país, mas deve considerar que são limitadas as possibilidades de expandir as áreas de cultivo e que cada uma de suas mesorregiões pode apresentar um comportamento distinto em relação a (des)valorização de suas terras agrícolas. Além disso, a conjuntura econômica pós Plano Real pode ter tido grande impacto nas alterações dos preços das terras paranaenses. Após um período de alta instabilidade econômica vivida entre as décadas de 1980 e início de 1990, as políticas econômicas pós Plano Real possibilitaram aos investidores maior segurança, tanto estrutural como econômica, que certamente impactaram no mercado paranaense de terras agrícolas. Nesse contexto, o objetivo principal do estudo foi analisar a evolução do preço das terras agrícolas no estado do Paraná e nas suas micro e mesorregiões entre 1998 e 2015. Além disso, o presente estudo tem por objetivo realizar uma análise de agrupamento de suas microrregiões em grupos homogêneos, tendo por parâmetro o grau de semelhança entre elas.

\section{MATERIAL E MÉTODOS}

Neste estudo foram utilizados dados de preços de terras agrícolas por hectare do Departamento de Economia Rural (DERAL), da Secretaria da Agricultura e do Abastecimento do Paraná (SEAB), referentes aos anos de 1998 a 2015. O período de observação está em consonância com a disponibilidade das informações.

Para as análises, foram considerados apenas os preços médios das terras agrícolas mecanizadas, por município. De acordo com o DERAL, estas são áreas destocadas, sem restrições para o preparo do solo e plantio, cuja declividade (topografia) permite operações com máquinas e implementos agrícolas motorizados, podendo ser cultivadas ou em pousio, independente da cultura existente, incluindo várzea sistematizada.

A partir dos dados por municípios foram calculados os valores médios dos preços das terras agrícolas para o Paraná, para as suas 10 mesorregiões (Centro Ocidental, Oeste, Centro Oriental, Noroeste, Metropolitana de Curitiba, Sudeste, Centro Sul, Norte Pioneiro, Norte Central e Sudoeste), e para 
as suas 39 microrregiões (Goioerê, Campo Mourão, Cascavel, Toledo, Foz do Iguaçu, Lapa, São Mateus do Sul, Paranaguá, Ibaiti, Wenceslau Braz, Pitanga, Prudentópolis, Telêmaco Borba, Jaguariaíva, Jacarezinho, Assaí, Cornélio Procópio, Porecatu, Londrina, Ponta Grossa, Umuarama, Cianorte, Astorga, Faxinal, Guarapuava, Curitiba, Ivaiporã, Capanema, Francisco Beltrão, Palmas, Pato Branco, Rio Negro, Irati, Paranavaí, União da Vitória, Cerro Azul, Floraí, Maringá e Apucarana).

Os valores monetários foram atualizados para dezembro de 2015, com base no Índice Nacional de Preços ao Consumidor Amplo (IPC-A), do IBGE, sendo este o índice oficial de inflação no Brasil.

Para verificar a correlação dos preços das terras agrícolas com as principais variáveis consideradas determinantes de seus preços, ou seja, Valor Bruto da Produção (VBP) da agricultura, crédito rural, taxa de câmbio (US\$/R\$), taxa de juros (SELIC) e taxa de inflação (IPC-A), foram realizadas análises a partir do coeficiente de correlação de Pearson. Para o teste de significância, foram consideradas as duas extremidades.

Por fim, para analisar o comportamento dos preços das terras agrícolas paranaenses em suas diversas regiões, foi feito uma análise de agrupamentos das microrregiões, pelo método de Ward, tendo por parâmetro o grau de semelhança entre elas. Trata-se de uma técnica estatística de interdependência que permite agrupar as variáveis em grupos homogêneos a partir de determinados parâmetros, conforme uma medida de similaridade, ou de distância (Fávero e Belfiore, 2015). Para esta análise foi considerado como variável os valores médios dos preços das terras agrícolas das 39 microrregiões do estado do Paraná referentes aos anos de 1998 a 2015. Para o processamento dos dados, foi utilizado o software SPSS 22.0, e para elaboração de mapas o software ArcGIS 10.2.

\section{RESULTADOS E DISCUSSÃO}

Na Figura 1 são apresentados os resultados referentes à evolução dos preços reais das terras agrícolas do Paraná, entre 1998 e 2015. Nesse ínterim, o preço médio das terras agrícolas paranaenses saltou de $\mathrm{R} \$ 7.073$ para $\mathrm{R} \$ 28.439$, correspondendo a um ganho real da ordem de $302,10 \%$ a uma taxa anual de crescimento de 8,53\%. Verifica-se que desde 1998, quando já vigorava o Plano Real, a evolução dos preços das terras agrícolas no Paraná apresentou diferentes comportamentos, sendo estes, em parte, reflexo direto de mudanças na conjuntura econômica brasileira.

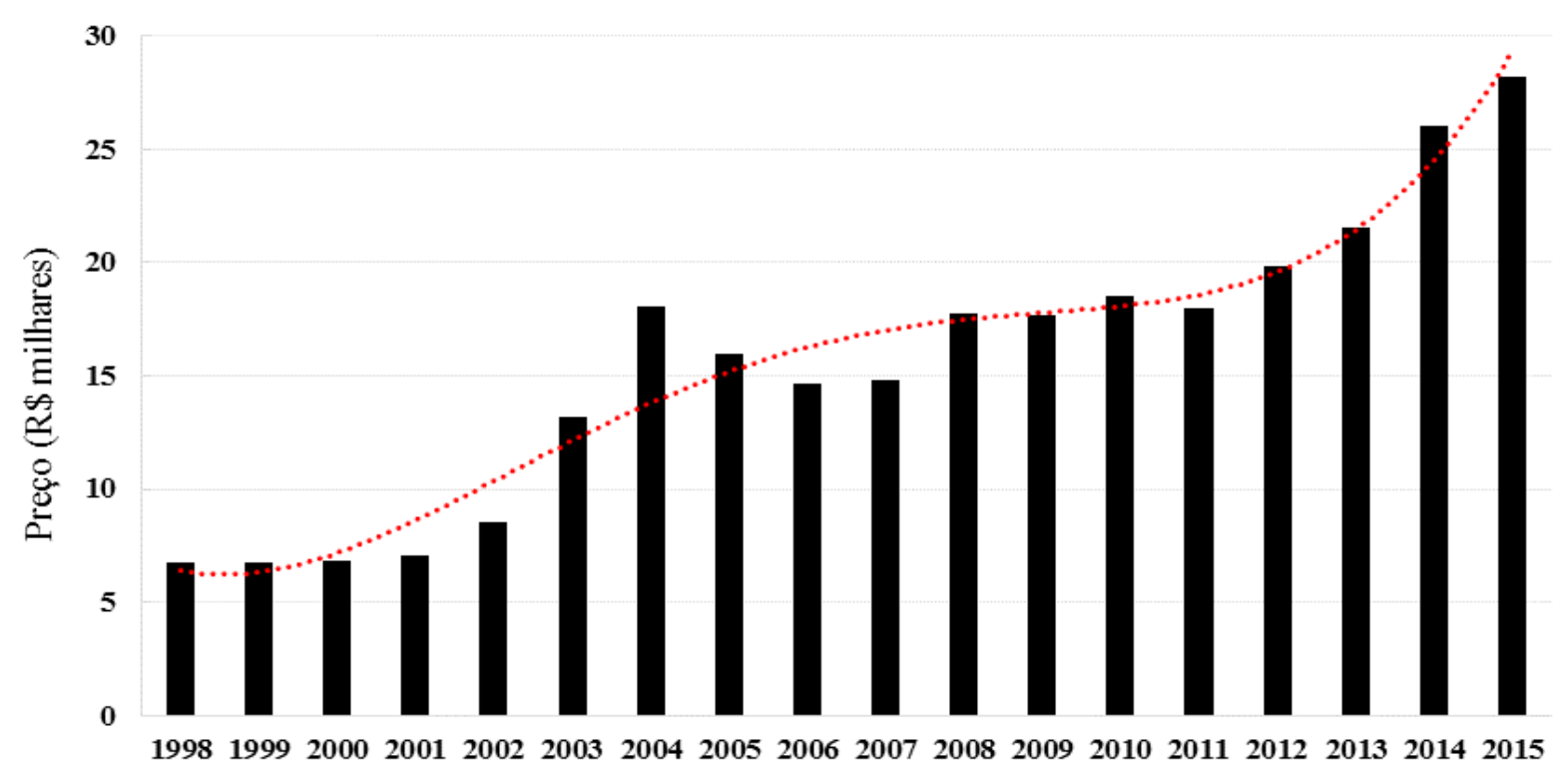

Fonte: Elaborado a partir dos dados do Departamento de Economia Rural (DERAL), da Secretaria da Agricultura e do Abastecimento do Paraná(SEAB) e Banco Central (BCB).

Figura 1 - Evolução dos preços das terras agrícolas no Paraná entre 1998 e 2015. 

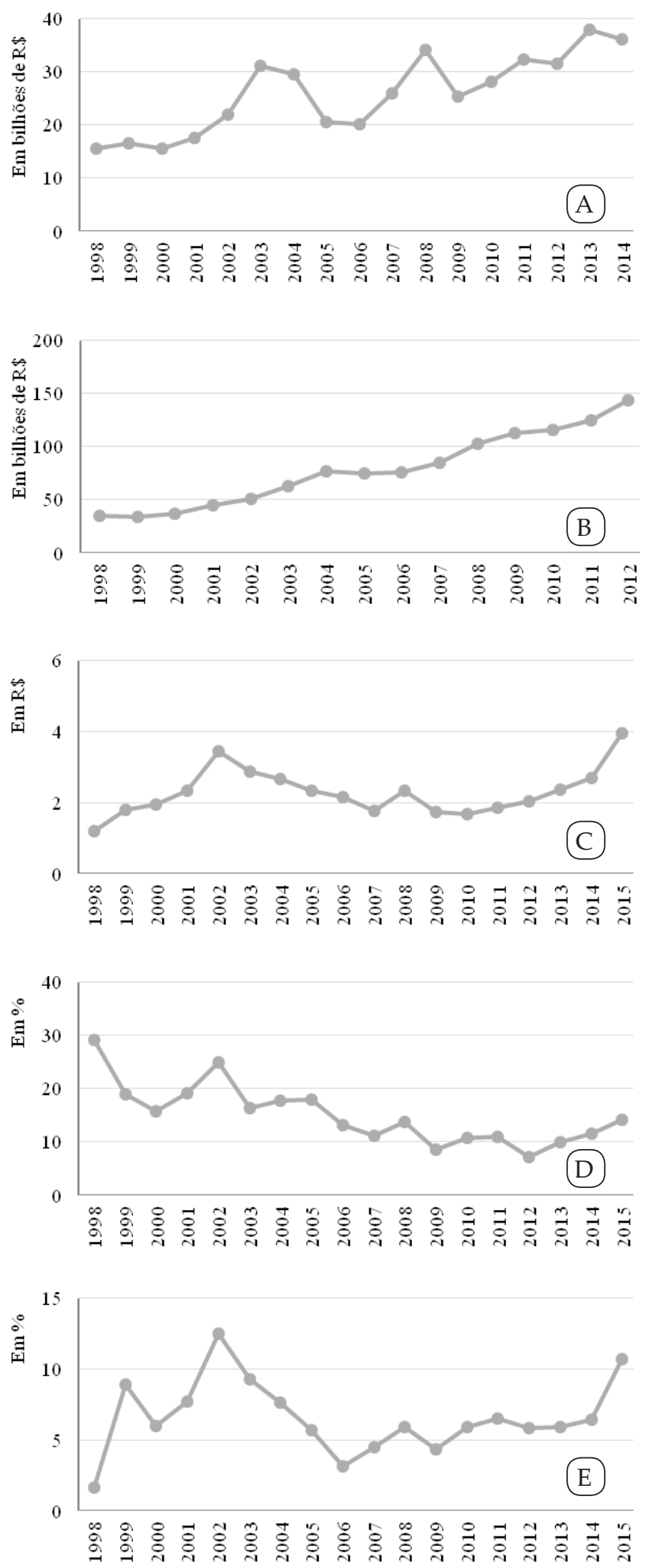

Fonte: Elaborado a partir dos dados do Departamento de Economia Rural (DERAL), da Secretaria da Agricultura e do Abastecimento do Paraná (SEAB) e Banco Central (BCB).

Figura 2 - Evolução do (a) Valor Bruto da Produção (VBP) da agricultura; (b) crédito rural; (c) taxa de câmbio (US\$/R\$); (d) taxa de juros (SELIC) e (e) taxa de inflação (IPC-A), entre 1998 e 2015.
Na Figura 2 é apresentado, para o período de 1998 a 2015, o comportamento de algumas variáveis para o entendimento da conjuntura econômica e que são consideradas determinantes dos preços das terras agrícolas, sendo elas o VBP da agricultura, o crédito rural, a taxa de câmbio (US\$/R\$), a taxa de juros (SELIC) e a taxa de inflação (IPC-A).

Entre 1998 e 2001, os preços das terras agrícolas paranaenses se mantiveram estáveis. Nesse intervalo de tempo, o preço médio das terras saltou de $\mathrm{R} \$ 7.073$ para $\mathrm{R} \$ 7.574$, apresentando uma valorização real de $7,83 \%$ a uma taxa anual de crescimento de 2,31\%. Esse comportamento pode estar relacionado ao fato de, em 1998, apesar do expressivo aumento na produção das lavouras brasileiras - sobretudo da soja, a renda bruta do produtor rural se manteve estável em relação ao ano anterior (Monteiro, 1999) - ou seja, não apresentou reflexos sobre os preços das terras agrícolas. Ainda nesse ano houve uma alta produção agropecuária, acompanhada de uma baixa demanda pelas commodities agrícolas que também podem ter sido responsáveis por manter os preços das terras estáveis. A partir de 1999 no Brasil, passou a ser adotado o regime de câmbio flutuante. Essa mudança no regime cambial foi um dos vetores da acentuada desvalorização do real frente ao dólar - queda de $72 \%$ entre dezembro de 1998 e janeiro de 1999 (BCB, 2016). Segundo Brandão et al. (2006), esse tipo de política econômica tende a afetar favoravelmente o setor agrícola, no entanto, não há na literatura uma análise mais detalhada, ainda mais quando se considera simultaneamente o comportamento da taxa de câmbio, dos preços das commodities agrícolas e da renda dos produtores rurais. Apesar da valorização do dólar frente ao real ser vantajosa para comercialização das commodities agrícolas e ganho relativo dos produtores, pode não afetar os custos de produção. Por isso é importante considerar os fluxos de caixa nas atividades agropecuárias nas análises sobre o mercado de terras.

No período de 2001 a 2004, houve uma acentuada elevação dos preços de terras agrícolas paranaenses. Nesse período, o valor médio saltou de $R \$ 7.574$ para $R \$ 19.141$, apresentando um ganho real de $152,71 \%$, ou seja, uma valorização anual de $36,21 \%$. Esse período foi marcado pelo aumento da demanda internacional por commodities agrícolas, fato responsável pela valorização 
das terras no estado. Com o aumento da demanda por commodities, sobretudo biocombustíveis, os mercados agrícolas no Brasil ficaram aquecidos e os preços dos produtos alcançaram níveis elevadíssimos (Gasques e Bastos, 2008). A justificativa mais provável para a elevação dos preços de terras agrícolas nesse intervalo de tempo está no aumento da procura por áreas de lavouras para o cultivo da soja, milho e cana-de-açúcar, marcada por mudanças no uso da terra - principalmente de pastagens para agricultura.

No Paraná, segundo dados da Produção Agrícola Municipal (PAM), do IBGE, foi registrada entre 1998 e 2001 uma taxa anual de crescimento de área plantada de soja de $1,65 \%$, enquanto que entre 2001 e 2004 foi apresentado um crescimento anual de $15,59 \%$. Neste período, o crescimento agrícola no Brasil se caracterizou por uma forte expansão da área total plantada de diferentes culturas, fugindo do padrão de crescimento agrícola perpetuado durante toda a década de 1990 (Brandão et al., 2006).

Além da demanda internacional por commodities agrícolas, a desvalorização cambial pode ter sido outro fator para a elevação da renda e dos preços das terras entre 2001 e 2004. Com uma política cambial de desvalorização do real frente ao dólar até 2004, as exportações agropecuárias do Brasil foram favorecidas, principalmente nas cadeias produtivas dos complexos soja e carnes. Nessa época, o câmbio desvalorizou $48,73 \%$. Outro fator que pode ter contribuído para a elevação do preço da terra foi o crédito rural. No Brasil, entre 2000 e 2007 , houve um aumento de $80,4 \%$ no volume de recursos concedidos via crédito rural aos produtores (Gasques e Bastos, 2008) - exemplo disto foi a criação do Programa de Modernização da Frota de Tratores e Máquinas Agrícolas (MODERFROTA).

Entre 2004 e 2008, não houve grande alteração no preço médio das terras agrícolas, passando de $\mathrm{R} \$ 19.141$ para $\mathrm{R} \$ 17.887$, uma desvalorização real de $6,55 \%$. Durante esse período, a agropecuária brasileira passou por inúmeras dificuldades. Segundo Paula (2006), embora a crise no agronegócio tenha se manifestado de modo diferente entre as regiões do país, o seu ponto mais frágil esteve situado entre os produtos vinculados ao complexo proteico, como a soja, o milho e as carnes. Além disso, houve a propagação da gripe aviária. Estes reveses contribuíram fortemente na redução do consumo de diferentes produtos e na redução da demanda por insumos, derivados de soja e milho, utilizados na alimentação de diferentes animais. Segundo o autor, entre janeiro e maio de 2005, o Produto Interno Bruto (PIB) nacional da agropecuária já havia apresentado uma redução, principalmente no segmento da agricultura, que foi afetado pelos baixos preços de algumas commodities agrícolas. Com base nos dados do Centro de Estudos Avançados em Economia Aplicada (CEPEA), entre 2004 e 2005, houve uma retração de $15,46 \%$ do PIB brasileiro da agricultura. Esse contexto afetou a agricultura paranaense, estreitamente relacionada ao cultivo de grãos.

No período de 2008 a 2011 os preços das terras agrícolas paranaenses se mantiveram estáveis. Nesse meio tempo, o preço médio das terras saltou de $\mathrm{R} \$ 17.887$ para $\mathrm{R} \$ 18.446$, apresentando uma valorização real de apenas 3,12\% a uma pífia taxa anual de crescimento de 1,03\%. Este período foi marcado pela crise financeira global de 2008. Mesmo com um cenário mundial desfavorável, um forte aumento dos preços internacionais das commodities agrícolas favoreceu as exportações. Segundo Telles et al. (2016), em 2008 e 2009 não houve uma queda dos preços de terras agrícolas, ao contrário, os preços se elevaram. Uma das hipóteses para esse fenômeno, segundo os autores, é que os agentes econômicos recorriam às terras como ativo com reserva de valor, a fim de se protegerem das incertezas geradas pela crise.

No último período analisado, 2011 a 2015, ocorreram mudanças significativas nos preços das terras agrícolas do Paraná. O preço médio destas saltou de $R \$ 18.446$ para $R$ \$ 28.439, apresentando uma valorização real de $54,17 \%$, a uma taxa anual de crescimento de $11,43 \%$. Os principais fatores que podem ter contribuído para tal aumento foram os ganhos produtivos associados aos bons preços das commodities agrícolas, em um cenário de desvalorização cambial (Aguiar et al., 2012), de 60,47\% (BCB, 2016). Além disso, a taxa de juros baixa estimulou a entrada de novos investidores ao mercado de terras e a aplicação de capital em terras por parte dos agricultores, mantendo os preços sólidos e em ascensão. 
No Quadro 1 são apresentados os coeficientes de correlação entre o preço das terras agrícolas e os seus principais determinantes, além dos seus respectivos níveis de significância. A partir do teste de correlação de Pearson, foi possível distinguir quais foram as variáveis que se relacionaram com maior intensidade com os preços das terras agrícolas, além de ser possível identificar quais delas apresentaram comportamentos inversos.

Quadro 1-Correlação do comportamento dos preços das terras agrícolas com seus principais determinantes

\begin{tabular}{lc}
\hline Variável & $\mathbf{R}^{\mathbf{2}}$ \\
\hline VBP da agricultura & $0,90^{*}$ \\
Crédito rural & $0,95^{*}$ \\
Taxa de câmbio (US\$/R\$) & 0,39 \\
Taxa de juros (SELIC) & $-0,68^{*}$ \\
Taxa de inflação (IPC-A) & 0,15 \\
\hline
\end{tabular}

Nota: * A correlação é significativa ao nível 1\%.

Fonte: Elaborado a partir dos dados do Departamento de Economia Rural (DERAL), da Secretaria da Agricultura e do Abastecimento do Paraná (SEAB) e do Banco Central do Brasil (BCB).

A correlação entre preço de terra e o VBP da agricultura paranaense foi de $90 \%(p \leq 0,01)$, evidenciando uma correlação muito forte e positiva. Assim como em Malassise et al. (2015), a variável VBP foi importante para explicar o comportamento dos preços das terras agrícolas no Paraná. Outra correlação expressiva entre o preço das terras agrícolas e o crédito rural, foi com poder explicativo de $95 \%$ ( $\mathrm{p} \leq$ 0,01), denotando uma correlação muito forte e positiva. Este resultado revela o papel importante que o crédito rural tem na determinação dos preços das terras agrícolas. Já a correlação entre preço de terra e câmbio apresentou um poder explicativo de 39\%, evidenciando uma correlação positiva e fraca. Em relação a correlação entre o preço das terras agrícolas e a taxa de juros SELIC, apresentou poder explicativo de $68 \%(\mathrm{p} \leq 0,01)$, denotando uma correlação negativa e moderada. Uma política de altas taxas de juros, pode ocasionar expectativas pessimistas de ganhos com a utilização produtiva da terra, desestimulando assim que novos investidores a adquiram para o seu portfólio. Ainda, juros altos podem tornar outros ativos econômicos mais atraentes. A correlação entre o preço de terra e a inflação foi de $15 \%$, ou seja, positiva e desprezível. Vale lembrar que no Brasil, durante os períodos de hiperinflação, entre as décadas de 1980 e 1990, os preços das terras agrícolas ascenderam a níveis elevados devido a sua capacidade de uso como reserva de valor. Os resultados obtidos mostram que, após o Plano Real, esta variável não conseguiu expressar correlação expressiva. Vale ressaltar que, tanto a taxa de juros quanto a inflação apresentam um gap temporal para que surtam algum efeito dentro de alguns setores da economia. Nesse sentido, uma correlação como a que foi realizada pode não expressar adequadamente a real associação entre estas variáveis e o preço das terras agrícolas, sendo necessário uma defasagem de tempo.

Para uma análise dos efeitos regionais no mercado de terras do Paraná, no Quadro 2 são apresentados os resultados da evolução dos preços reais das terras agrícolas nas suas mesorregiões e suas correspondentes microrregiões, entre 1998 e 2015. De modo geral, a evolução dos preços reais das terras agrícolas nas mesorregiões paranaenses ocorreu de modo similar ao observado para o estado. No entanto, as terras agrícolas nas mesorregiões Sudeste, Sudoeste, Centro Sul, Centro Ocidental, Centro Oriental e Noroeste se valorizaram acima da taxa anual observada para o Paraná (8,53\%). Esta valorização acima da média anual paranaense pode estar associada aos melhores tipos de terras e a estrutura de governança local ligada ao agronegócio.

A mesorregião Sudeste foi a mais valorizada entre 1998 e 2015, onde apresentou uma taxa anual de crescimento de $11,06 \%$, tendo acumulado um ganho real de $494,88 \%$. No entanto, mostrou-se o menor preço médio de terra ao longo do período, sendo cotada em 2015 a $R \$ 20.057$. A região Sudeste é formada por quatro microrregiões, destas somente São Mateus do Sul e União da Vitória apresentaram taxa anual de crescimento acima da média. O maior destaque foi a microrregião de União da Vitória que apresentou taxa anual de crescimento de $15,46 \%$, acumulando assim um ganho real de $1051,96 \%$ no período - sendo a mais valorizada no estado. Entretanto possuiu o menor preço médio de terra da mesorregião, sendo cotada em 2015 a R\$ 17.784. As microrregiões do Sudeste são historicamente destacadas por apontarem uma 


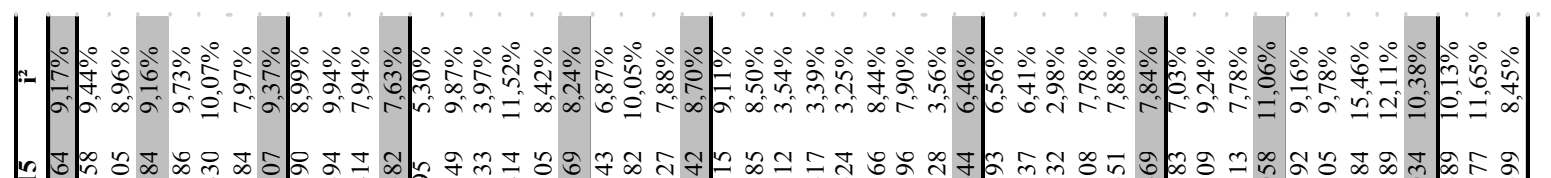

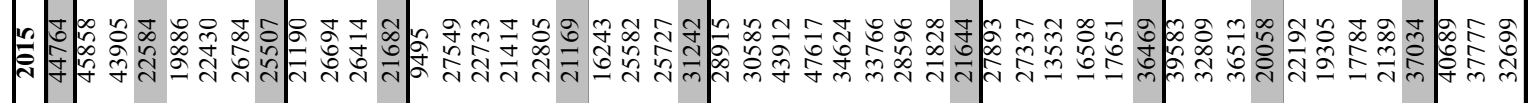

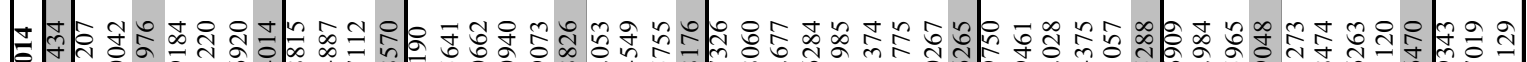

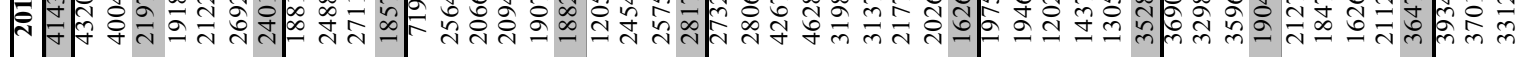

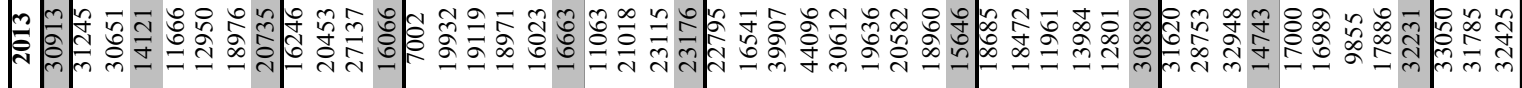

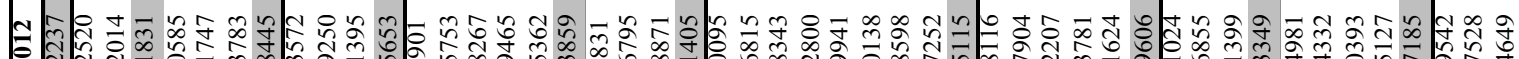

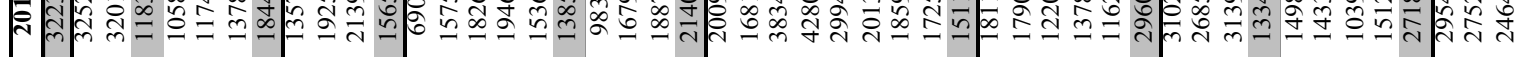

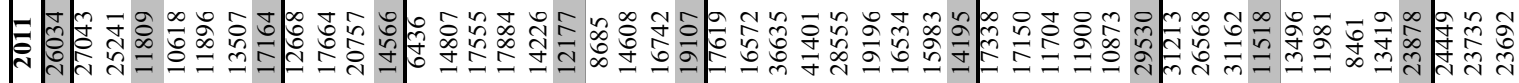

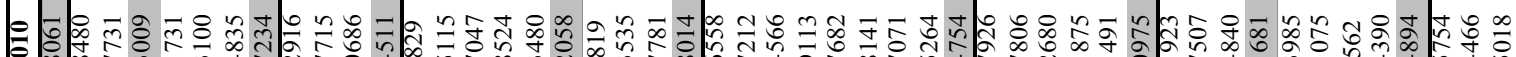

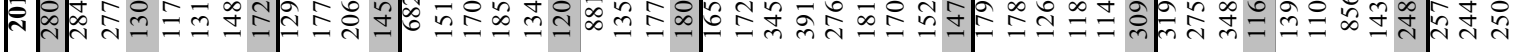

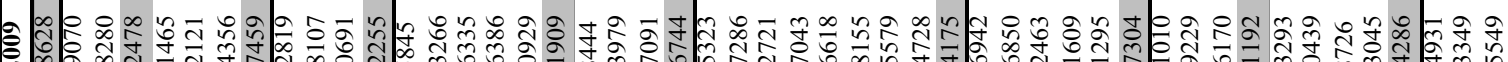

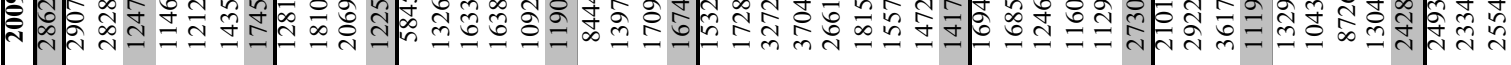

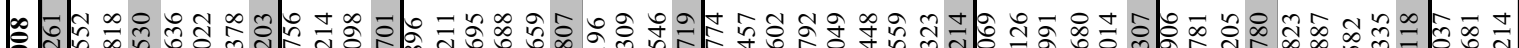
A

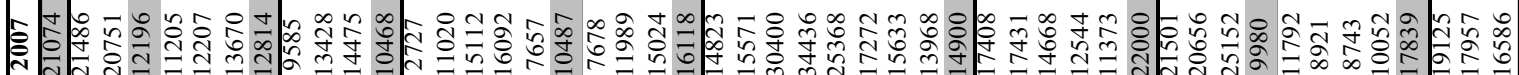

(1)

要

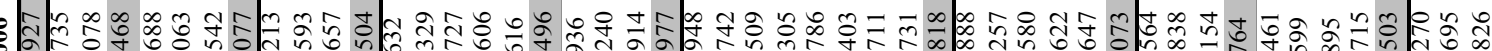
空

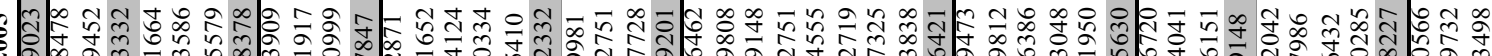

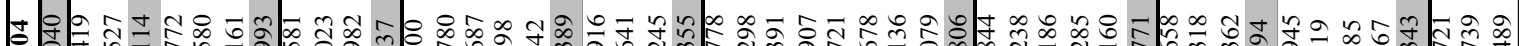

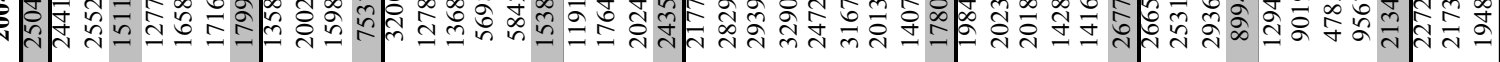

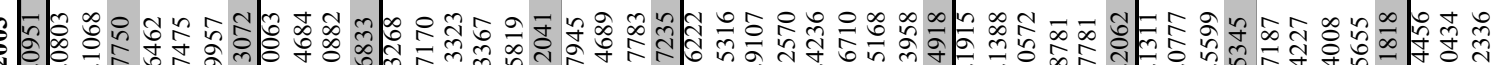

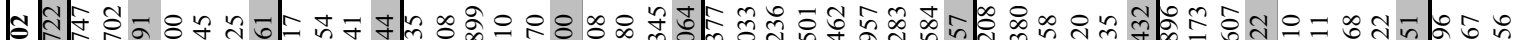

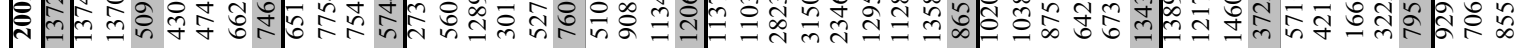

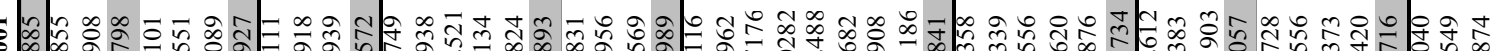

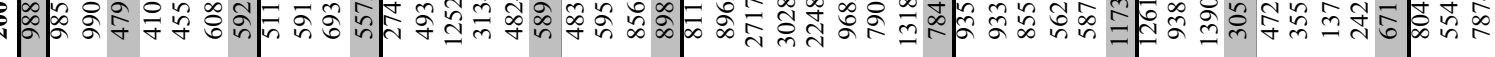

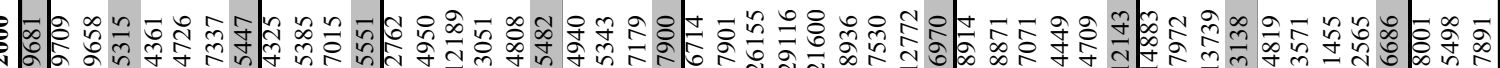

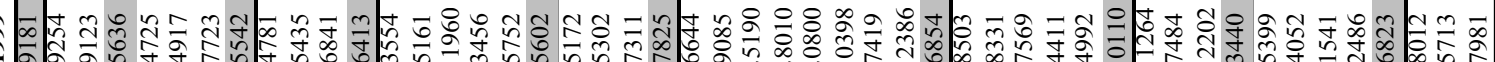

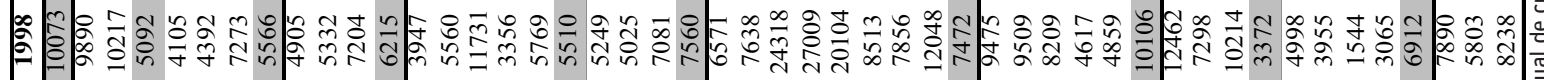
.
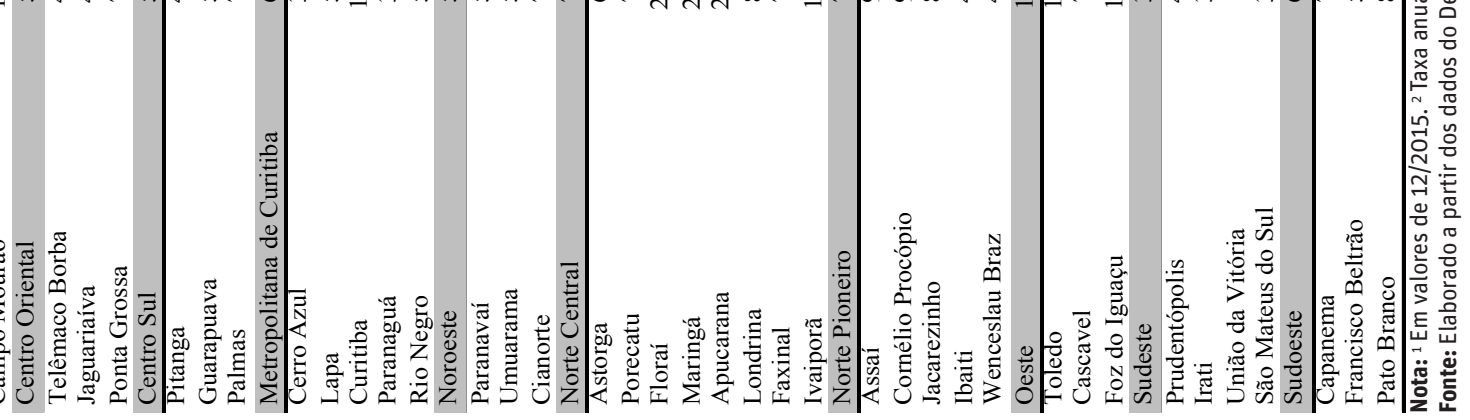
agricultura familiar de baixo padrão tecnológico (Llanillo et al., 2006), além disso, são formadas por terras de qualidades inferiores e de condições edafoclimáticas desfavoráveis ao cultivo de grãos, principal commoditie agrícola do estado.

Com uma taxa anual de crescimento do preço de terras agrícolas de 10,38\%, a região Sudoeste evidenciou um ganho real de $435,79 \%$. Em 2015, o preço médio das terras foi de $\mathrm{R} \$ 37.034$, ou seja, 31,26\% acima da média do estado. Nessa região predominam as pequenas unidades produtivas, mas em função do padrão de governança regional associado às grandes cooperativas agrícolas, a produção se realiza de forma organizada e assentada sob elevado padrão tecnológico (Santos, 2011). A mesorregião Sudoeste está localizada próxima de outras duas mesorregiões que também apresentaram preços de terras elevados, a Centro Ocidental e a Oeste.

Em 2015, o preço médio das terras da mesorregião Centro Ocidental foi de R $\$ 44.764$, ou seja, 57,4\% acima da média estadual, com uma taxa anual de crescimento de $9,17 \%$. A mesorregião tem se destacado por apresentar um bom desempenho relacionado à produção de grãos, como a soja e o milho. Composta por apenas duas microrregiões, Campo Mourão e Goioerê, são consideradas umas das mais importantes na agricultura paranaense. Estas apontaram uma taxa anual de crescimento acima do estado, 8,96\% e 9,44\%, respectivamente.

A mesorregião Oeste, em 2015, apresentou um preço médio de terras de $R \$ 36.469$, ou seja, 28,23\% acima do valor médio do estado. Com uma taxa anual de crescimento de 7,84\%, acumulou no período um ganho real de 260,85\%, devido a suas microrregiões, Toledo e Foz do Iguaçu, apresentarem taxas abaixo da verificada para o estado. A agricultura dessa mesorregião está vinculada a um complexo agroindustrial moderno e competitivo, estruturado aos eixos dinâmicos do país e do exterior (Melo e Parré, 2007).

Entre 1998 e 2015, a mesorregião Norte Central apresentou uma taxa anual de crescimento de $8,7 \%$, tendo acumulado um ganho real de $313,25 \%$. No ano de 2015, o preço médio das terras foi de $\mathrm{R} \$ 31.242$, ou seja, 9,85\% acima do peço médio do estado. Esta fundamentou-se essencialmente na agropecuária e agroindústria, com ênfase nas culturas de soja, milho e fruticultura (Pinto et al., 2014). Formada pelo maior número de microrregiões do Paraná, a região Norte Central é composta por oito microrregiões que apresentaram taxa anual de crescimento abaixo da verificada no estado, com exceção da microrregião Astorga, com 9,11\%. Quanto as demais microrregiões Apucarana, Floraí, Maringá e Ivaiporã apresentaram a menor taxa anual de crescimento, sendo estas 3,25\%, $3,39 \%, 3,54 \%$ e $3,56 \%$ respectivamente, enquanto que as microrregiões Faxinal, Londrina e Porecatu apresentaram taxas mais próximas do estado, sendo estas $7,90 \%, 8,44 \%$ e 8,50\% respectivamente. A microrregião de Maringá, apesar de apresentar uma das menores taxas de crescimento do preço de terra durante o período, em 2015 foi a que possui preço mais caro do Paraná, cotada a $\mathrm{R} \$ 47.617$.

A mesorregião Centro Sul apresentou uma taxa anual de crescimento de $9,37 \%$, tendo acumulado um ganho real de $358,23 \%$ no período. Embora tenha apresentado uma taxa acima do Paraná, o seu preço médio ficou abaixo do estado, sendo cotada em 2015 a R $\$ 25.507$. Segundo Melo e Parré (2007), esta região é considerada uma das menos urbanizadas, com elevado número de assentamentos rurais e de áreas indígenas, fatores que podem refletir no mercado de terras local.

A mesorregião Centro Oriental apresentou uma taxa anual de crescimento de 9,16\%, tendo acumulado um ganho real de $343,49 \%$ no período. O processo de modernização da agricultura possibilitou aos produtores desenvolverem uma produção intensiva em capital, incorporando na pauta agrícola regional a produção de soja, trigo e milho. Embora tenha ocorrido esse desenvolvimento na região, em 2015, o preço médio das terras foi de $\mathrm{R} \$ 22.584$, ou seja, 20,58\% abaixo da média do Paraná. A mesorregião Centro Oriental é formada por três microrregiões. Telêmaco Borba e Jaguariaíva apresentaram taxa anual de crescimento de $9,73 \%$ e $10,07 \%$, respectivamente, sendo assim, apenas a microrregião Ponta Grossa apresentou uma taxa abaixo do verificado na mesorregião de 7,97\%. Esta região é marcada pela agropecuária de baixa modernização com matas nativas.

Apesar de suas terras estarem localizadas próximas ao sistema portuário e de um grande centro consumidor, a mesorregião Metropolitana de Curitiba, não apresentou preços de terras elevados. Em 2015, o preço médio foi de $\mathrm{R} \$ 21.682$, ou seja, $23,75 \%$ abaixo da média estadual. A taxa anual de crescimento para o período foi de $7,63 \%$, tendo acumulado um ganho 
real de $248,87 \%$. Trata-se de uma região formada por uma extensa área de solos inaptos ao uso agropecuário, caracterizada pela baixa fertilidade, suscetíveis a erosão e alta declividade (IPARDES, 2004a). Esses atributos são alguns dos fatores que limitam o desenvolvimento agrícola na região e que ajudam a entender parcialmente os preços das terras. A mesorregião Metropolitana de Curitiba é formada por cinco microrregiões. Destas, as microrregiões Curitiba e Cerro Azul apresentaram taxa anual de crescimento muito abaixo do verificado para a mesorregião, sendo $3,97 \%$ e 5,30\%, respectivamente. A microrregião Cerro Azul apresentou o menor preço médio de terras do Paraná, cotado no ano de 2015 a R \$ 9.494.

A mesorregião Noroeste apresentou uma taxa anual de crescimento de $8,24 \%$, acumulando um ganho real de $284,19 \%$ no período. No entanto, seus preços de terras estão $25,56 \%$ abaixo da média estadual, visto que em 2015, foi de R\$21.169. Das três microrregiões, Umuarama, Paranavaí e Cianorte, apenas a primeira apresentou taxa anual de crescimento acima do estado com 10,05\%. A mesorregião Noroeste apresenta limitações ao uso do solo, associadas às extensas áreas do arenito Caiuá, que inviabiliza a expansão de culturas anuais (Pinto et al., 2014). Devido a isso tem se destacado pelas pastagens plantadas e pecuárias bovinas extensivas.

Considerada a mesorregião que menos valorizou entre 1998 e 2015, a Norte Pioneiro apresentou uma taxa anual de crescimento de 6,46\%, acumulando um ganho real de $189,67 \%$ no período. Em 2015, o preço médio das terras foi de $\mathrm{R} \$ 21.644$, apresentando um valor 25,56\% abaixo da média do estado. As terras localizadas a oeste da região, derivadas de basalto, possuem boa fertilidade natural e topografia mais plana, dando condições propícias ao cultivo de soja e milho altamente tecnificados. Já as terras encontradas a leste, por possuírem solos formados por rochas sedimentares de baixa fertilidade natural, com pouca profundidade e topografia tendendo para acidentada, não foram inclusas no processo de modernização agrícola da região (IPARDES, 2004b). A mesorregião Norte Pioneiro é formada por cinco microrregiões e todas apresentaram taxa anual de crescimento abaixo do verificado para o Paraná. Entre elas, Jacarezinho se destacou por apresentar a menor taxa anual de crescimento do estado com 2,98\%, e um dos menores preços de terras do Paraná, sendo que em 2015, foi de $\mathrm{R} \$ 13.532,46$.
Mesmo em um estado como o Paraná, onde a agricultura tem grande destaque na economia, a modernização da agropecuária se deu de modo desigual entre suas regiões, sendo possível observar que aquelas que apresentam melhores condições edafoclimáticas indicam uma agricultura mais representativa e com terras mais valorizadas.

Nas Figuras 3 e 4 são apresentados, respectivamente, o dendograma de formação de clusters e o mapa com os agrupamentos das microrregiões paranaenses em função da evolução dos preços reais das terras agrícolas e da taxa anual de valorização, entre 1998 e 2015. A partir do grau de similaridades foram identificados seis grupos que se formaram em função da evolução dos preços reais das terras agrícolas. O Grupo 1 foi composto por 5 microrregiões, o Grupo 2 por 10 microrregiões, o Grupo 3 por 12 microrregiões, o Grupo 4 por 4 microrregiões, o Grupo 5 por 5 microrregiões e o Grupo 6 por 3 microrregiões.

No Grupo 1 estão associadas as microrregiões com as terras agrícolas mais caras, o qual se verificou um complexo agroindustrial moderno e competitivo. Neste, a taxa anual de valorização das terras ficou próxima àquela verificada para o estado. Outro aspecto é que a partir de 2003, ano que favoreceu o mercado internacional de commodities, os preços das terras deste grupamento quase que duplicaram.

O Grupo 2 foi formado por microrregiões com preços de terras abaixo da média paranaense. A diferença em relação aos outros grupos da mesma faixa de preço foi que, a partir de 2004, seus preços duplicaram. Este grupo concentra as microrregiões onde predominam a agricultura familiar de baixa e média intensidade (Llanillo et al., 2006).

O Grupo 3 foi composto por áreas que apresentaram preços de terras agrícolas próximas da média estadual. Embora nestas áreas haja uma grande extensão de solos de boa qualidade, há também terras de qualidade inferior, podendo justificar seus preços médios. Além disso, estão incluídas as microrregiões que tiveram taxas de crescimento do preço das terras agrícolas inferiores ao verificado para o estado. Neste grupamento estão inseridas regiões de pastagens de baixa e média modernização.

No Grupo 4, formado por microrregiões com terras de preços elevados, predominam solos de boa qualidadee 


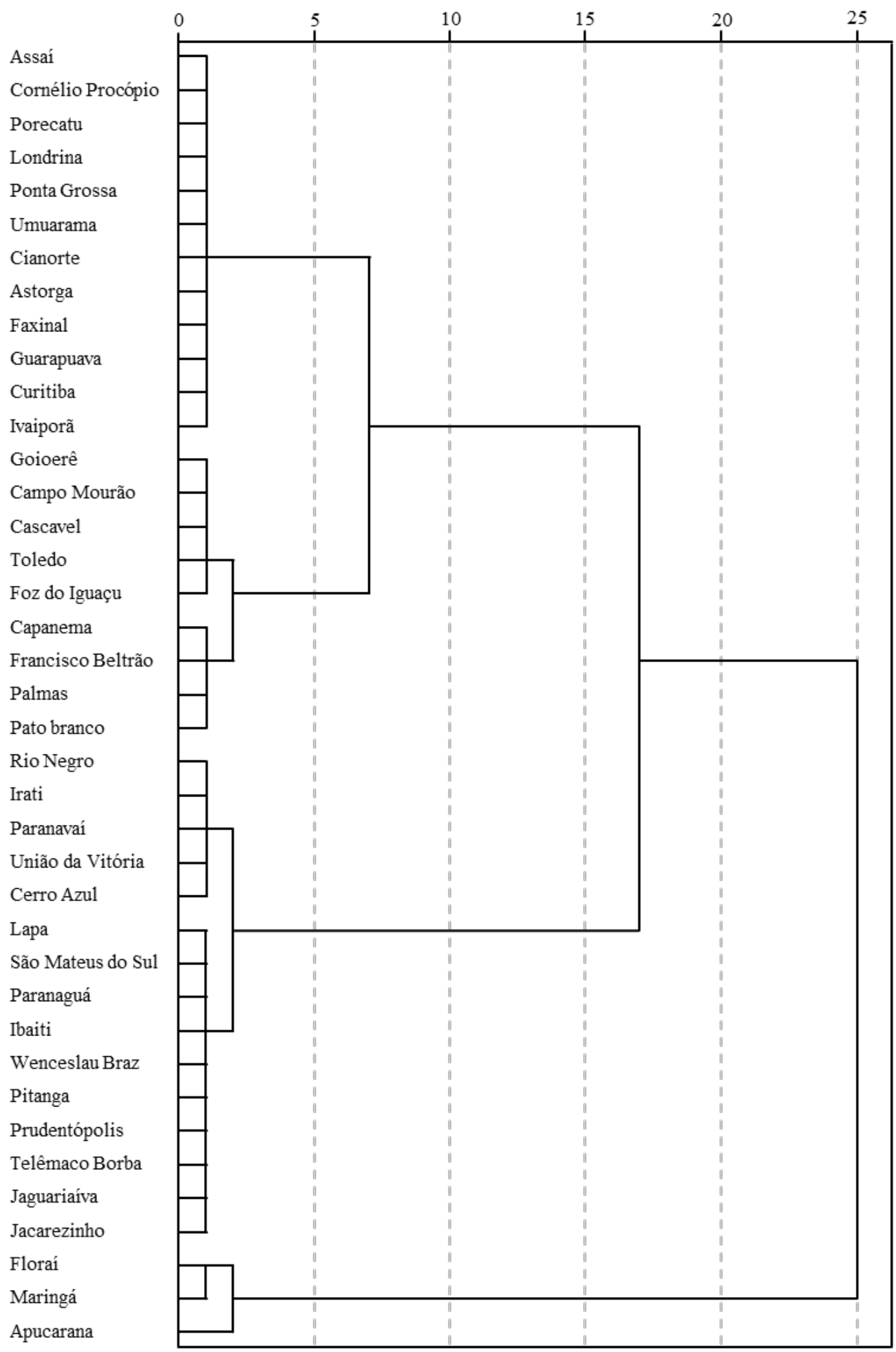

Fonte: Elaborado pelos autores.

Figura 3 - Dendograma de formação de clusters das microrregiões paranaenses em função da evolução dos preços reais das terras agrícolas entre 1998 e 2015. 


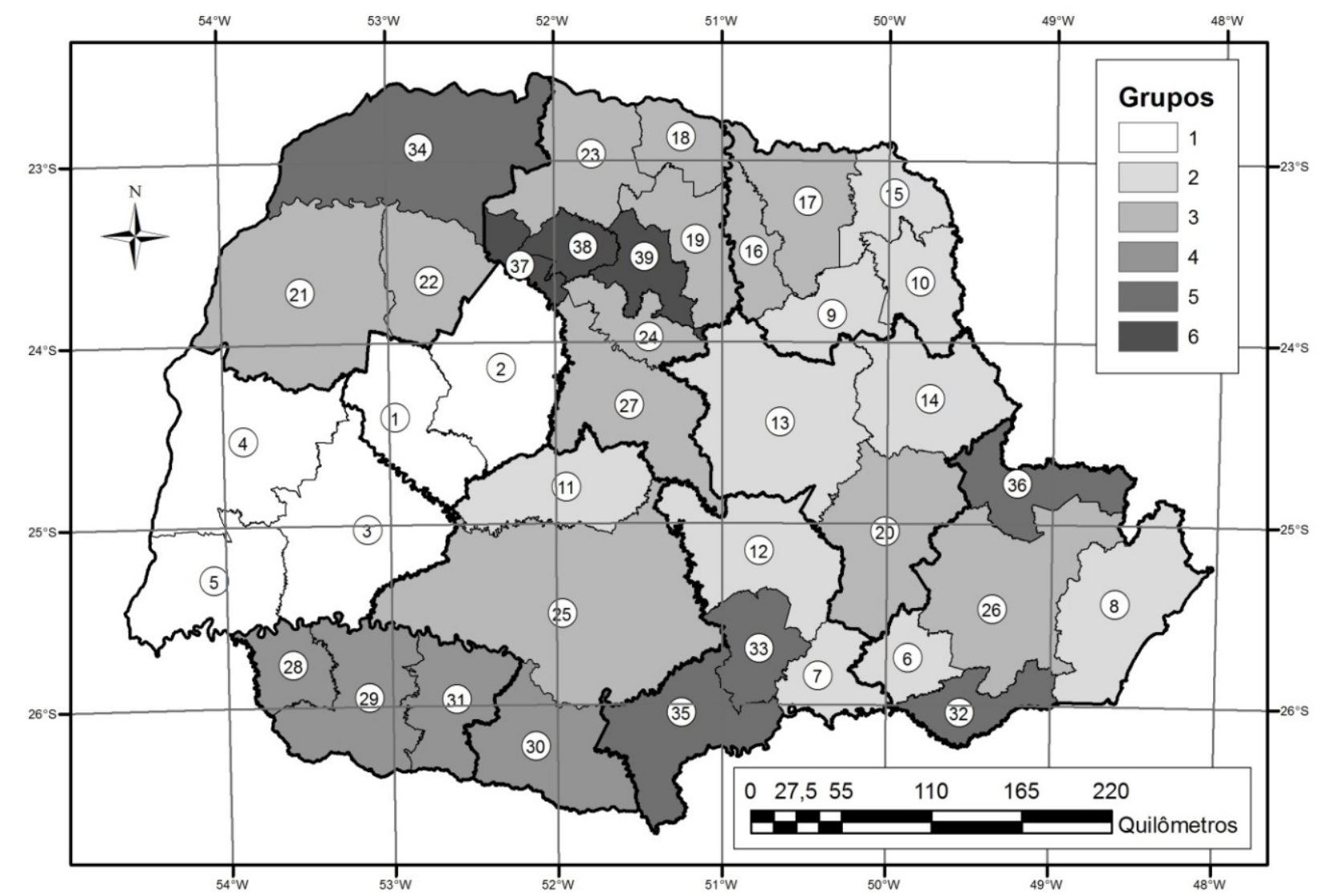

Fonte: Elaborado pelos autores.

Nota: 1. Goioerê, 2. Campo Mourão, 3. Cascavel, 4. Toledo, 5. Foz do Iguaçu, 6. Lapa, 7. São Mateus do Sul, 8. Paranaguá, 9. Ibaiti, 10. Wenceslau Braz, 11. Pitanga, 12. Prudentópolis, 13. Telêmaco Borba, 14. Jaguariaíva, 15. Jacarezinho, 16. Assaí, 17. Cornélio Procópio, 18. Porecatu, 19. Londrina, 20. Ponta Grossa, 21. Umuarama, 22. Cianorte, 23. Astorga, 24. Faxinal, 25. Guarapuava, 26. Curitiba, 27. Ivaiporã, 28. Capanema, 29. Francisco Beltrão, 30. Palmas, 31. Pato Branco, 32. Rio Negro, 33. Irati, 34. Paranavaí, 35. União da Vitória, 36. Cerro Azul, 37. Floraí, 38. Maringá, 39. Apucarana.

Figure 4 - Mapa de agrupamento das microrregiões paranaenses em função da evolução dos preços reais das terras agrícolas entre 1998 e 2015.

condições propícias ao cultivo de grãos. Ele difere por apresentar até ao ano de 2003 preços de terras abaixo da média estadual - que se elevam a partir de 2004. Além disso, as microrregiões que compõem esse agrupamento, embora tenham passado por transformações na sua base produtiva, com a introdução de novas práticas de cultivo a partir da expansão da soja, correspondem a um importante reduto da agricultura familiar (Melo e Parré, 2007).

O Grupo 5 foi composto pelas terras mais baratas do Paraná, a exemplo da microrregião de Cerro Azul, que apresentou o menor preço de terras. Os baixos preços podem ser explicados em decorrência das terras estarem localizas em regiões de condições edafoclimáticas menos propícias ao cultivo das principais commodities agrícolas do estado e, até mesmo, com severas restrições ao desenvolvimento de atividades agropecuárias. Todavia, cabe lembrar que a microrregião de União da Vitória, embora esteja inserida entre as terras mais baratas do estado, foi a que mais valorizou no período analisado.

O Grupo 6 também foi formado pelas terras mais caras do estado. Neste grupo estão concentradas as três microrregiões que apresentaram os preços mais elevados da mesorregião Norte Central, estando incluída entre elas, a microrregião de Maringá, que apresentou o maior preço de terra do estado. Apesar de ter apresentado um preço de terra bastante elevado, a taxa anual de crescimento foi a menor verificada no estado, variando entre 3,25\% e 3,54\%. É formado por regiões de agricultura moderna. 


\section{CONCLUSÕES}

A evolução e o comportamento dos preços das terras agrícolas no estado Paraná e em suas regiões denotam que as variáveis ligadas à produção agrícola, embora importantes, não são suficientes para explicar as mudanças verificadas entre 1998 e 2015.

Visto que as atividades agrícolas no Paraná já estão consolidadas, sem grandes possibilidades de se expandir para novas áreas, os aspectos macroconjunturais da economia brasileira têm influenciado as alterações no mercado paranaense de terras.
Em relação às variações nos preços das terras agrícolas nas micro e mesorregiões do Paraná, naquelas em que há uma estrutura de governança mais consolidada, mesmo diante de conjunturas econômicas desfavoráveis, inclusive em relação às commodities agrícolas, o mercado segue uma dinâmica diferente daquela que seria a esperada - preços dos produtos agrícolas versus preços das terras agrícolas.

Vislumbra-se que o padrão de governança ligado ao agronegócio, nos diversos níveis ou dimensões do espaço geográfico, deva ser incorporado nas discussões acerca do mercado de terras agrícolas no país.

\section{REFERÊNCIAS BIBLIOGRÁFICAS}

Aguiar, G.A.M.; Lima Filho, R.R. \& Torres Junior, A.M. (2012) - Preços garantem remuneração de capital. Agroanalysis, vol. 32, n. 10, p. 25-26.

BCB. (2016) - Banco Central do Brasil. Câmbio e capitais internacionais: taxas de câmbio. [cit. 2016.01.11]. http://www. bcb.gov.br>. Acesso em 11 jan. 2016.

Brandão, A.S.P.; Rezende, G.C. \& Marques, R.W.C. (2006) - Crescimento agrícola no período 1999/2004: a explosão da soja e da pecuária bovina e seu impacto sobre o meio ambiente. Economia Aplicada, vol. 10, n. 2, p. 249-266. http://dx.doi.org/10.1590/S1413-80502006000200006

Camargo, A.M.M.P.; Camargo, F.P.;Siqueira, A.C.N.; Camargo Filho, W.P. \& Francisco, V.L.F.S. (2004) - Valorização da terra agrícola conforme o uso regional do solo no estado de São Paulo. Informações Econômicas, vol. 34, n. 1, p. 28-40.

Fávero, L.P. \& Belfiore, P. (2015) - Análise de dados: técnicas multivariadas exploratórias. Rio de Janeiro, Elsevier, $368 \mathrm{p}$.

Ferro, A.B. \& Castro, E.R. (2013) - Determinantes dos preços de terras no Brasil: uma análise de região de fronteira agrícola e áreas tradicionais. Revista de Economia e Sociologia Rural, vol. 51, n. 3, p. 591-609. http://dx.doi.org/10.1590/ $\underline{\text { S0103-20032013000300010 }}$

Gasques, J.G. \& Bastos, E.T. (2008) - Terra: preços no Brasil. Agroanalysis, vol. 28, n. 4, p. 14-18.

IPARDES. (2004a) - Leituras regionais: Mesorregião Geográfica Metropolitana de Curitiba. Instituto Paranaense de Desenvolvimento Econômico e Social, Curitiba.

IPARDES. (2004b) - Leituras regionais: Mesorregião Geográfica Norte Pioneiro Paranaense. Instituto Paranaense de Desenvolvimento Econômico e Social, Curitiba.

Llanillo, R.F.; Del Grossi, M.E.; Santos, F.O.; Munhos, P.D. \& Guimarães, M.F. (2006) - Regionalização da agricultura do Estado do Paraná, Brasil. Ciência Rural, vol. 36, n. 1, p. 120-127. http://dx.doi.org/10.1590/S0103-84782006000100018

Malassise, R.L.S. Parré, J.L. \& Fraga, G.J. (2015) - O comportamento do preço da terra agrícola: um modelo de painel de dados espaciais. Revista de Economia e Sociologia Rural, vol. 53, n. 4, p. 645-666. http://dx.doi. org/10.1590/1234-56781806-9479005304005

Melo, C.O. \& Parré, J.L. (2007) - Índice de desenvolvimento rural dos municípios paranaenses: determinantes e hierarquização. Revista de Economia e Sociologia Rural, vol. 45, n. 2, p. 329-365 http://dx.doi.org/10.1590/ $\underline{\text { S0103-20032007000200005 }}$

Michellon, E. \& Reydon, B.P (2003) - O mercado de terras e o manejo do solo e da água em microbacias hidrográficas: o caso do Paraná Rural. Acta Scientiarum: Human and Social Sciences, vol. 25, n. 1, p. 175-184. http://dx.doi. org/10.4025/actascihumansoc.v25i1.2209 
Monteiro, M.J.C. (1999) - Terra sem promessas. Agroanalysis, vol. 19, n. 4, p. 17.

Oliveira, N.A.P \& Ferreira, L.R. (2014) - Determinantes do preço da terra no Brasil. Revista de Política Agrícola, vol. 23, n. 4, p. 58-75.

Paula, N. (2006) - Crise e desafios do agronegócio brasileiro. Economia e Tecnologia, vol. 5, p. 93-98. http://dx.doi. org/10.5380/ret.v2i2.29476

Pinto, N.G.M.; Lopes, M.M.L. \& Coronel, D.A., (2014) - Análise da degradação ambiental nos municípios e Mesorregiões do estado do Paraná. Revista Paranaense de Desenvolvimento, vol. 35, n. 126, p. 191-206.

Reydon, B.P. \& Plata, L.E.A. (2006) - O plano real e o mercado de terras no Brasil: lições para a democratização do acesso à terra. In: Reydon, B.P. \& Cornélio, F.N.M (Orgs.) - Mercados de terras no Brasil: estrutura e dinâmica. Brasília: NEAD, p. 267-284.

Reydon, B.P.; Plata, L.E.A.; Sparovek, G.; Goldszmidt, R.G.B. \& Telles, T.S. (2014) - Determination and forecast of agricultural land prices. Nova Economia, vol. 24, n. 2, p. 389-407. http://dx.doi.org/10.1590/0103-6351/1304

Santos, R.A. (2011) - Território e modernização da agricultura no Sudoeste do Paraná. Revista Espaço Acadêmico, vol. 10, n. 118, p. 114-122.

Telles, T.S.; Palludeto, A.W.A. \& Reydon, B.P. (2016) - Price movement in the Brazilian land market (1994-2010): an analysis in the light of post-Keynesian theory. Revista de Economia Politica, vol. 36, n. 1, p. 109-129. http://dx.doi. org/10.1590/0101-31572016v36n01a07 